\title{
Interferon alpha in subacute sclerosing panencephalitis: Case report and review of the literature
}

\author{
K Moodleya ${ }^{a}$ PLA Billa and VB Patela* \\ ${ }^{a}$ Department of Neurology, University of KwaZulu-Natal, Durban, South Africa \\ *Corresponding author, email: kaminiemoo@ialch.co.za
}

Subacute Sclerosing Panencephalitis (SSPE) is a rare, rapidly progressive neurodegenerative disease caused by the measles virus. Spontaneous remission and survival longer than 4 years is rare. The disease commonly affects children and adolescents from less privileged socio-economic backgrounds. Prior to immunisation, the incidence of SSPE in South Africa (SA) was 2.6/100 000 people per year, which is higher than the global estimate of $1 / 1000000$ per year. The post-immunisation incidence has dropped to $0.43 / 100000$ people per year. Currently, there is no curative treatment for SSPE. In developed countries, patients have been treated with antiviral therapy and interferon alpha (IFN $\alpha$ ) with promising results. There have been no reported studies of children with SSPE treated with IFN $\alpha$ in South Africa. We report on a patient successfully treated with intraventricular INF $\alpha$.

Keywords: Subacute Sclerosing Panencephalitis (SSPE), Interferon, HIV, Measles

\section{Introduction}

Subacute Sclerosing Panencephalitis (SSPE) is a rare, rapidly progressive neurodegenerative disease. Spontaneous remission and prolonged survival of more than 4 years is rare. ${ }^{1}$ SSPE is caused by an RNA virus, which belongs to the morbillivirus subgroup of the paramyxoviridae family. ${ }^{2}$ Infection of the brain occurs during acute exanthem by direct infection of cerebral endothelial cells or via circulating inflammatory cells. Contiguous spread is by transynaptic cell to cell transmission. Mutations in the outer envelope proteins results in abnormal viral fusion and budding. ${ }^{2}$ The exact factors that influence viral persistence are unclear, but several immunological factors including low cerebrospinal fluid interferon (IFN) levels have been implicated. ${ }^{2}$ Other risk factors for the disease are acquiring measles infection as an infant, male gender, low birth weight, overcrowding and lack of immunisation against measles especially in developing countries. ${ }^{2}$ The disease was first described by Dawson in $1933 .^{3}$ Since then several clinical reports from the West and more recently the East have appeared in the literature. Very few cases have been described from Africa. In Africa, the most notable reports have been from Kenya ${ }^{4,5}$ and South Africa. ${ }^{5-10}$ Single case reports have

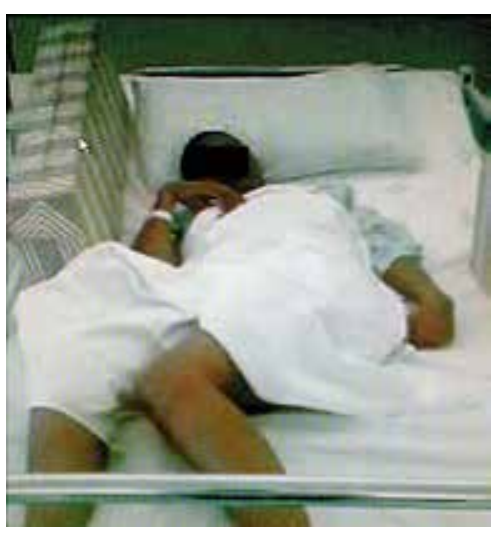

Figure 1: Patient was quadrispastic and bedbound.

been from Tanzania, ${ }^{11}$ Nigeria ${ }^{12}$ and Ethiopia. ${ }^{13}$ In South Africa, the largest series has been from Moodie et al. ${ }^{6}$ who reported 116

Table 1: Summary of epidemiological characteristics of described SSPE cases from published South African studies'

\begin{tabular}{|c|c|c|c|c|c|c|}
\hline Reference & Year of data collection & Area & Total number of cases & SSPE incidence ${ }^{a}$ & No of cases by race & Age \\
\hline 9,10 & $1971-1974$ & Cape Province & 15 & 1.2 & $9 \mathrm{M}, 6 \mathrm{~B}$ & $3-13$ \\
\hline 14 & $1955-1974$ & Southern Africa ${ }^{b}$ & 79 & ND & $36 \mathrm{~W}, 23 \mathrm{M}, 20 \mathrm{~B}$ & $1-23$ \\
\hline 14 & $1955-1975$ & Southern Africa ${ }^{b}$ & 96 & $M, 15.9^{c}, W, 2.9^{c}$ & $30 \mathrm{~W}, 30 \mathrm{M}, 26 \mathrm{~B}$ & $1-23$ \\
\hline 6 & $1955-1980$ & Southern Africa ${ }^{b}$ & 116 & $M: 2.6^{c}, W: 1.47^{c}$ & ND & ND \\
\hline 7 & 1984-1987 & South Africa & 44 & Overall: $0.43, \mathrm{~W}: 0.63, \mathrm{~B}: 0.36$ & $12 \mathrm{~W}, 32 \mathrm{~B}$ & $3-27$ \\
\hline 8 & 1984-1990 & South Africa & 75 & ND & $16 \mathrm{~W}, 5 \mathrm{M}, 53 \mathrm{~B}$ & $2-29$ \\
\hline 10 & 1982-1987 & KwaZulu Natal & 18 & ND & $17 \mathrm{~B}, 1 \mathrm{~A}^{\mathrm{d}}$ & $4-14$ \\
\hline
\end{tabular}

aNumber of cases per 100000 people per year. W: white; M: Mixed; B: Black; ND: not done

bIncludes Zimbabwe, Namibia and Malawi

'Age Specific (0-24yrs) incidence, Cape Province only (1970-1976)

${ }^{\mathrm{d} A}$ : Asian However no cases have been documented regarding successful treatment of patients with SSPE from Africa. To our knowledge this is the first documented case using intraventricular interferon alpha in Africa 


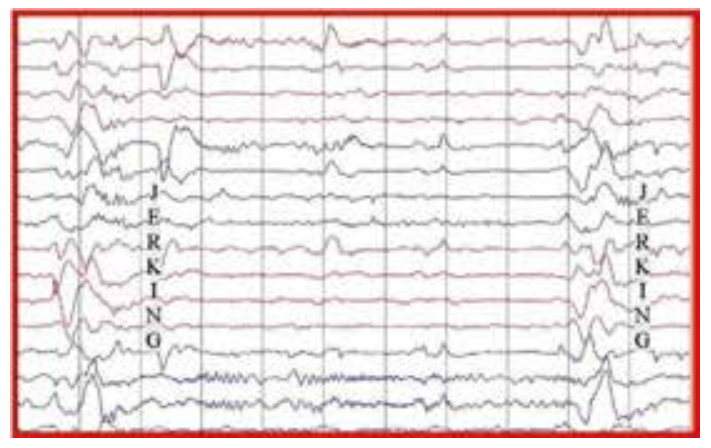

Figure 2: EEG shows a slow background with periodic complexes coincident with patient's jerks.

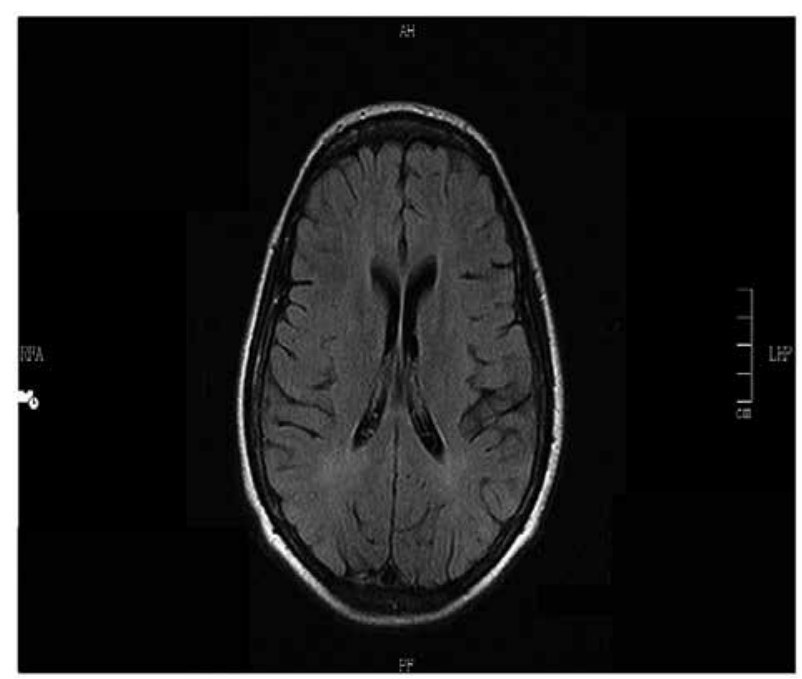

Figure 3: MRI brain at admission shows periventricular white matter hyperintensities.

cases of SSPE. Other cases in South Africa are from Carman et al., ${ }^{7}$ Schoub et al., ${ }^{8}$ McDonald et al. ${ }^{9}$ and Moodley et al. ${ }^{10}$ (Table 1).

\section{Case report}

The patient was a 19-year-old black African woman who presented in 2006 with a 3-year history of worsening myoclonic jerks of her body. Her family noticed intellectual and psychosocial declines over 3 years. Her scholastic performance had significantly declined requiring her to repeat several years at school. In the last 6 months prior to admission, she complained of deteriorating vision. She had had measles at 4 months of age and needed hospitalisation. She was not vaccinated against measles as an infant.

On examination she had intermittent myoclonic jerks of all her extremities at intervals of 10 to $15 \mathrm{~s}$. Her height and head circumference were normal for her age. Her general examination and systemic examination were normal. She was conscious and aware of her environment but unable to speak. She could obey simple verbal commands. Cranial nerve examination revealed bilateral optic atrophy and slow saccadic eye movements. Motor examination revealed quadrispasticity with dystonic posturing of the right toe. Her reflexes, including her jaw jerk, were brisk; and, she had bilateral extensor plantar responses. Her power, sensation and coordination could not be assessed. She was unable to stand or walk (Figure 1).

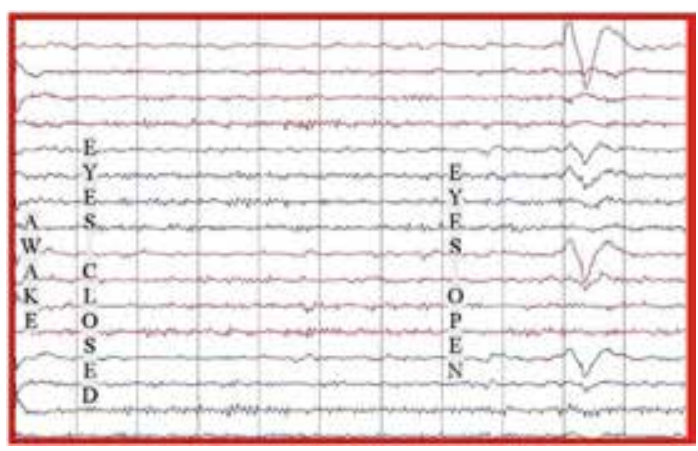

Figure 4: EEG at 9 months post treatment (July 2007) showing significant improvement in the EEG with a normal background without periodic complexes.

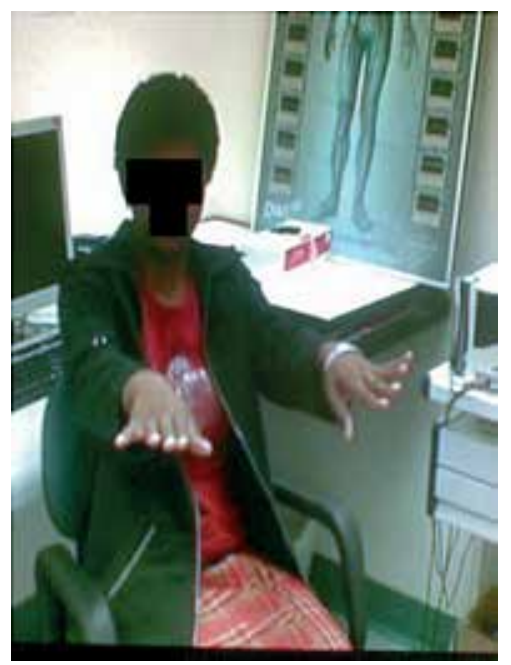

Figure 5: Patient is well, able to walk and converse normally and has no myoclonic jerks.

The electroencephalogram (EEG) showed a slow background with intermittent bursts of periodic large amplitude complexes occurring every 10 to15 s, coincident with the myoclonic jerks (Figure 2). There was no epileptiform activity or asymmetry. The history, clinical and laboratory findings (Table 2) were diagnostic of Stage 3a SSPE. ${ }^{4}$ Measles-specific cerebrospinal spinal fluid (CSF) oligoclonal bands were positive. We were unable to acquire measles IgG titres in the CSF or serum. An MRI of her brain at admission showed periventricular white matter hyperintensities (Figure 3).

In view of her advanced disease, we opted to treat her with intraventicular interferon alpha at a dose of 1.5 million units on alternate days for 6 weeks through an Ommaya Reservoir. Increased somnolence was the main side effect that she experienced. Her response to treatment was monitored clinically, electrophysiologically and serologically.

Four weeks into her treatment she showed remarkable improvement. She was able to communicate fluently. Her spasticity and myoclonic jerks had resolved. She was able to walk unaided. Her EEG improved, showing a normal background with no periodic bursts (Figure 4). Repeat neuropsychometric tests and the Neurology Disability Index confirmed significant improvement over time when compared to her baseline. Her mini-mental state examination (MMSE) improved from 12/30 to 


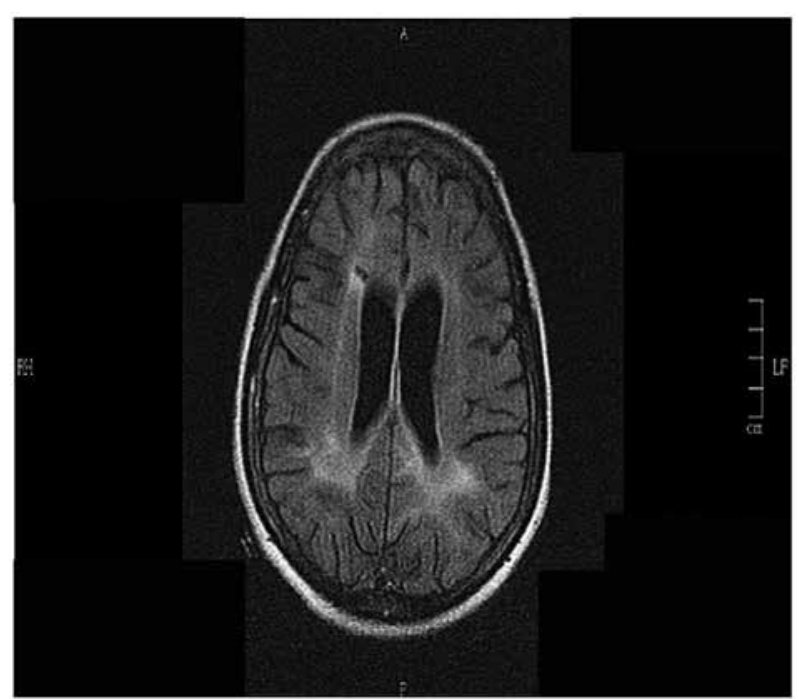

Figure 6: Brain MRI 30 months after treatment (April 2008), showing progressive periventricular white matter hyperintensities.

$22 / 30$ four months post treatment, and was normal at 9 months post treatment (Figure 5). At 9 months post treatment, a repeat CSF examination for measles IgG antibodies was negative. She remained well for the next 30 months post treatment. She returned home where she was able to perform activities of daily living. She later returned to school, was able to interact with her peers and learn new information.

Table 2: Investigations on admission

\begin{tabular}{|c|c|c|}
\hline Blood tests & & Reference ranges \\
\hline Haemoglobin & $13.3 \mathrm{~g} / \mathrm{dl}$ & $12-15 \mathrm{~g} / \mathrm{dl}$ \\
\hline Platelets & $397 \times 10^{9}$ cells $/ \mathrm{l}$ & $186-450 \times 10^{9}$ cells $/ \mathrm{l}$ \\
\hline White blood cell count & $5 \times 10^{9}$ cells $/ \mathrm{l}$ & $4-12 \times 10^{9}$ cells $/ \mathrm{l}$ \\
\hline Erthrocyte sedimentation rate & $56 \mathrm{~mm} / \mathrm{hr}$ & $0-10 \mathrm{~mm} / \mathrm{hr}$ \\
\hline Urea and electrolytes & Normal & \\
\hline Calcium, magnesium and phosphate & Normal & \\
\hline Thyroid function test & Normal & \\
\hline Copper & Normal & \\
\hline Caeruloplasmin & Normal & \\
\hline Human immunodeficiency virus (X2) & Negative & \\
\hline Rapid Plasma Reagin test & Negative & \\
\hline Antinuclear factor & Negative & \\
\hline Measles lgG & Positive & \\
\hline \multicolumn{3}{|l|}{ Cerebral spinal fluid } \\
\hline Protein & $0.08 \mathrm{~g} / \mathrm{l}$ & $0.15-0.45 \mathrm{~g} / \mathrm{l}$ \\
\hline Globulins & Not increased & \\
\hline Glucose & $5.3 \mathrm{mmol} / \mathrm{l}$ & $2.2-3.9 \mathrm{mmol} / \mathrm{l}$ \\
\hline PCR (HSV, CMV, HZ, enteroviruses) & Negative & \\
\hline Cytology & Negative & \\
\hline Measles-specific oligoclonal bands & Positive & \\
\hline Measles-specific ELISA antibodies & Positive & \\
\hline \multicolumn{3}{|l|}{ Imaging } \\
\hline CT brain & Normal & \\
\hline MRI & White matter hyperintensities & \\
\hline CXR & Normal & \\
\hline
\end{tabular}

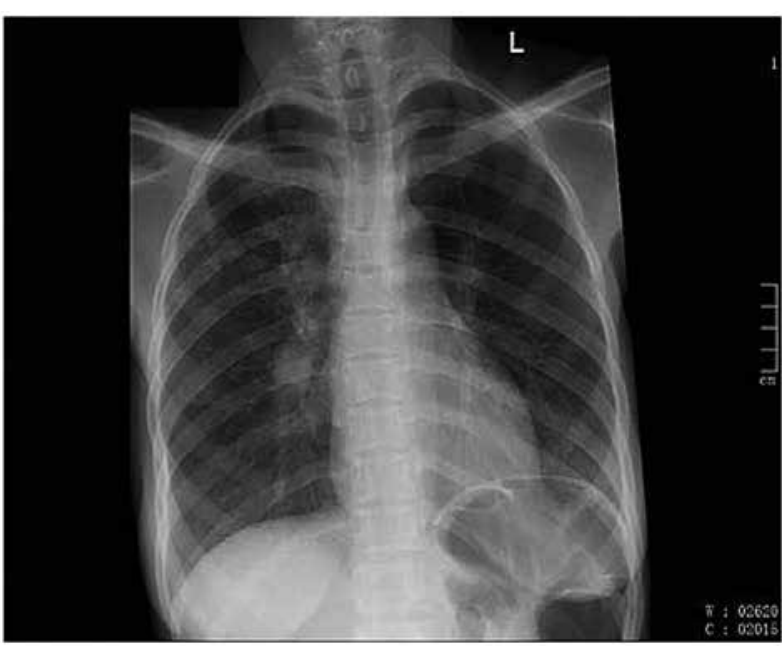

Figure 7: Chest X-ray 30 months after treatment (April 2008), showing hilar infiltrates.

Subsequently, she deteriorated cognitively and was unable to talk, walk or interact with her environment. She developed myoclonic jerks. She was readmitted for a relapse of her SSPE which was confirmed by recurrence of her periodic complexes on a slow EEG background, and her repeat measles specific antibodies in the CSF were again positive. 
Table 3: Outcome of patients treated with intraventricular IFN $\alpha$

\begin{tabular}{|c|c|c|c|c|c|c|}
\hline Author & Reference & $\begin{array}{c}\text { Place and date of } \\
\text { study }\end{array}$ & $\begin{array}{c}\text { Number of } \\
\text { patients }\end{array}$ & $\begin{array}{l}\text { Maximum } \\
\text { dosage }\end{array}$ & $\begin{array}{l}\text { Duration of } \\
\text { follow up }\end{array}$ & Outcome \\
\hline Banu Anlar et al. & 24 & Turkey(1986-1991) & 22 & I MU/week & 56-108 months & $\begin{array}{c}50 \% \text { Remission, } 22 \% \\
\text { Stabilised, } 28 \% \\
\text { Progressed }\end{array}$ \\
\hline Masahito Miyazaki & 25 & Japan(1985-2003) & 1 & $3 \mathrm{MU} /$ week & 18 years & Remission for 8 years \\
\hline Panitchi & 26 & Japan(1986) & 3 (Stage $2 / 3$ ) & unknown & \pm 2 years & $100 \%$ Remission \\
\hline Steiner & 27 & Israel(1989) & 3 & $1 \mathrm{MU}$ twice/week & \pm 2 years & $100 \%$ remission \\
\hline Kurata & 28 & Japan & 1 (Stage 2B) & $3 \mathrm{MU} /$ week & 6 months & Improved \\
\hline Horiquchi & 29 & Japan & 1 & $6 \mathrm{MU} /$ week & 4 years & Improved \\
\hline
\end{tabular}

Magnetic resonance imaging (MRI) of her brain showed multiple $\mathrm{T} 2$ and flair hyperintensities in the periventricular regions with extension into centrum semi-ovale (Figure 6). She was given 3 doses of intraventricular interferon alpha but continued to deteriorate. Her chest radiograph was suggestive of pulmonary tuberculosis (PTB) (Figure 7), despite there being no microbiological confirmation of the disease. A human immunodeficiency virus (HIV) test, which was initially negative, was now positive. Her CD4 count was 160 cells $/ \mathrm{mm}^{3}$ and her viral load was 17000 copies $/ \mathrm{ml}$. The interferon alpha was discontinued as we were unsure of its effect on HIV or PTB. She was commenced on antituberculosis treatment, empirical cotrimoxazole for possible cerebral toxoplasmosis and Pneumocystis carinii chest infection. She was not commenced on antiretrovirals as she was significantly ill at this stage and may have deteriorated further with a possible immune reconstitution inflammatory syndrome (IRIS), or from side effects of the drug. Despite the above treatment she continued to deteriorate and later demised. The family refused a postmortem examination.

\section{Discussion}

No curative therapy is currently available for SSPE. Suggested pharmacological management includes disease modifying agents and symptomatic treatment. Disease modifying treatment includes antiviral agents, such as isoprinosine and interferon alpha administered via the intraventricular route. Thus far the most promising results are seen with interferon alpha administered via the intraventricular route. Interferon alpha activates natural killer (NK) cells and directly inhibits viral replication. Studies have shown that interferon alpha levels are low in patients with SSPE and in vitro studies of patient-derived peripheral mononuclear cells fail to produce interferon alpha in response to stimulation. Exogenous interferon alpha may potentiate the activity of NK cells and promote clearance of the virus. ${ }^{15}$

Various studies listed in Table 3 demonstrate the benefit of intraventricular interferon alpha. However, most of the above are limited to case reports. These studies show that remission rates are still far higher than documented spontaneous remission rates of $5-10 \% .^{15}$

Results are highly variable using antiviral drugs alone. Jones et al. ${ }^{16}$ reported that inosiplex prolongs survival in SSPE. Other studies ${ }^{17}$ showed that inosiplex had no benefit when compared to controls. This is contrary to a large international multicentre study by Gascon ${ }^{18}$ consisting of 121 patients randomised to either inosiplex (62 patients) or combined inosiplex and interferon alpha (59 patients). This study showed no statistical difference between the
2 treatment groups implying that inosiplex used alone is also efficacious. The above studies demonstrate that treatment induced remission, approximately $35 \%$, is far higher than the 5-10\% documented spontaneous remission.

High dose Ribavirin combined with intravenous (IV) IFN also showed improvement in 2 patients. ${ }^{19,20}$ Smaller studies using combination therapy with inosiplex and lamuvidine with subcutaneous interferon alpha showed no benefit compared to control groups. ${ }^{21}$

Cimetidine ${ }^{22}$ and IV gammaglobulin ${ }^{23}$ also showed no benefit.

Our patient is the first documented case of successful treatment with intraventricular IFN $\alpha$ in Africa. Our patient unfortunately demised at 30 months post treatment, possibly related to complications of acquired HIV as an opportunistic disease. Whether the HIV infection accelerated the replication of the measles virus, or whether she relapsed due to treatment failure remains uncertain. Recent case reports have suggested that there is an increase incidence of SSPE in the HIV-positive population, ${ }^{30,31}$ and that the presentation of SSPE may be more fulminant in the setting of HIV. ${ }^{30,31}$ Therefore, it is possible that her relapse may have been accelerated by her HIV co-infection.

Furthermore, it is possible that the measles infection resulted in accelerated progression of her HIV as she rapidly developed Stage 4 AIDS within a short space of time.

\section{Conclusion}

The above case as well as various other case reports and studies indicate that intraventricular IFN $\alpha$ is able to positively alter the natural history of a fatal disease. Even though treatment induced remissions are temporary, the impact it has on patients' lives is clinically significant and may last for several years. The role of interferon alpha in measles encephalitis may extend beyond SSPE to other forms of measles encephalitides, such as inclusion body encephalitis. Further randomised trials are needed to evaluate the use of interferon alpha alone or in combination with other antiviral or immune modulating drugs in SSPE and other measles encephalitides. This is necessary to clearly establish its efficacy, effective dose, duration of treatment and define retreatment strategies. The cost of treatment, however, remains prohibitive for developing countries.

The outcome in this patient is unfortunate and is a learning curve in terms of counselling our patients against the common ills in South Africa, especially against preventable diseases such as HIV. 


\section{Financial disclosure}

The above authors have no financial interest in the above article.

\section{References}

1. Vardas E, Leary PM, Yeats J. Case report and molecular analysis of SSPE in a SA child. J Clin Microbiol. 1999;37:775-777.

2. Garg R. Subacute sclerosing panencephalitis. Postgraduate Med J. 2002;78:63-70.

3. Dawson JR. Cellular inclusions in cerebral lesions of epidemic encephalitis. Arch Neurol Psychiatry. 1934;31:685-700.

4. Dixit V, Hettiaratchi $E$, Muoka T. A study of subacute sclerosing panencephalitis in Kenya. Dev Medicine \& Child Neurol. 1981;23:208-16.

5. Tukei $P$, Kenya $P$, Ensering $H$. An epidemiological study of subacute sclerosing panencephalitis in Kenya. East Afr Med J. 1983;60:34-8.

6. Moodie J, Mackenzie D, Kipps A. Subacute sclerosing panencephalitis (SSPE) in southern Africa. S Afr Med J. 1980;58:964-7.

7. Carman W, Johnson S. Subacute sclerosing panencephalitis in South Africa. Trans R Soc Trop Med Hyg. 1989;83:117-8.

8. Schoub BD, Johnson S, McAnerney JM. Observations of subacute sclerosing panencephalitis in South Africa. Trans R Soc Trop Med Hyg. 1992;86:550-1.

9. McDonald R, Kipps A, Leary P. Subacute sclerosing panencephalitis in the Cape Province. S Afr Med J. (1974);48:7-9.

10. Moodley M, Moosa A. Subacute sclerosing-panencephalitis in black children-A review of 18 CASES. QJM. 1990;76:845-54.

11. Munube G, David J, Kimati V. Subacute sclerosing panencephalitis in Tanzania: Report of a first case. East Afr Med J. 1979;56:347-352.

12. Izuora G, Okoro A, Mordi V. Subacute sclerosing panencephalitis (SSPE) in a Nigerian teaching hospital. East Afr Med J. 1981;58:848851.

13. Gebremariam A, Lulseged S, Tamrat A. Subacute sclerosing panencephalitis (SSPE) in an adolescent Ethiopian girl. Ann Trop Paediatr. 1987;7:262-3.

14. Kipps A, MacKenzie D, McDonald R. Register of cases of subacute sclerosing panencephalitis (SSPE) in Southern Africa. Cardiovasc Surg. 1977;72:756

15. Risk WS, Haddad FS. The variable natural history of subacute sclerosing panencephalitis. Arch Neurol. 1979;36:610-4.

16. Jones $C$, Huttenlocher P, Dyken P, et al. Inosiplex therapy in subacute sclerosing panencephalitis. The Lancet 1982;319:1034-7.

17. Haddad FS, Risk WS. Isoprinosine treatment in 18 patients with subacute sclerosing panencephalitis: A controlled study. Ann. Neurol. 1980;7:185-8

18. Gascon GG. Randomized treatment study of inosiplex versus combined inosiplex and intraventricular interferon- $\alpha$ in subacute sclerosing panencephalitis (SSPE): International multicenter study. J Child Neurol. 2003;18:819-27.

19. Hara $S$, Kimura $H$, Hoshino $Y$, et al. Combination therapy with intraventricular interferon- $\alpha$ and ribavirin for subacute sclerosing panencephalitis and monitoring measles virus RNA by quantitative PCR assay. Brain Develop. 2003;25:367-9.

20. Hosoya M, Shigeta S, Mori S, et al. High-dose intravenous ribavirin therapy for subacute sclerosing panencephalitis. Antimicrob Agents Chemother. 2001;45:943-5.

21. Aydin OF, Senbil N, Kuyucu N, et al. Combined treatment with subcutaneous interferon- $\alpha$, oral isoprinosine, and lamivudine for subacute sclerosing panencephalitis. J Child Neurol. 2003;18:104-8.

22. Anlar B, Gücüyener K, Imir T, et al. Cimetidine as an immunomodulator in subacute sclerosing panencephalitis. Pediatr Infect Dis J. 1993;12:578-81.

23. Yavuz Gürer Y, Kükner Ş, Sarica B. Intravenous $\gamma$-globulin treatment in a patient with subacute sclerosing panencephalitis. Pediatr Neurol. 1996;14:72-4.

24. Anlar B, Yalaz K, Oktem F, et al. Long-term follow-up of patients with subacute sclerosing panencephalitis treated with intraventricular alpha-interferon. Neurology. 1997;48:526-8.

25. Miyazaki $M$, Nishimura $M$, Toda $Y$, et al. Long-term follow-up of a patient with subacute sclerosing panencephalitis successfully treated with intrathecal interferon alpha. Brain Develop. 2005;27:301-3.

26. Panitch H, Gomez-Plascencia J, Norris F, et al. Subacute sclerosing panencephalitis: Remission after treatment with intraventricular interferon. Neurology. 1986;36:562-6.

27. Steiner I, Wirguin I, Morag A, et al. Intraventricular Interferon treatment for subacute sclerosing panencephalitis. J Child Neurol. 1989;4:20-4.

28. Kurata T, Matsubara E, Yokoyama M, et al. Improvement of SSPE by intrathecal infusion of -IFN. Neurology. 2004;63:398-9.

29. Horiguchi $Y$, Ohya T. Successful treatment of subacute sclerosing panencephalitis with long-term intrathecal large dose of alpha-interferon - A case report. No to Hattatsu Brain Develop. 1995;27:231-7.

30. Gowda VK, Sukanya V, Shivananda. Acquired immunodeficiency syndrome with subacute sclerosing panencephalitis. Pediatr Neurol. 2012;47:379-81.

31. Sivadasan A, Alexander $M$, Patil AK, et al. Fulminant subacute sclerosing panencephalitis in an individual with a perinatally acquired human immunodeficiency virus infection. Arch Neurol. 2012;69:1644-7. 